\title{
APLICAÇÃO DE UM MODELO DE LOCALIZAÇÃO PARA A QUESTÃO LOGÍSTICA DA SOJA BRASILEIRA: UMA INDICAÇÃO DE LOCALIZAÇÃO PARA ARMAZÉNS.
}

\author{
Calistênia Santana Mascarenhas \\ Universidade Estadual de Campinas \\ cali.smascarenhas@gmail.com \\ Bruna Fernanda Ribeiro Lopes \\ Universidade Estadual de Campinas \\ brufribeiro@yahoo.com.br \\ Jamile de Campos Coleti \\ Universidade Estadual de Campinas \\ jamile.coleti@gmail.com \\ Andréa Leda Ramos de Oliveira \\ Universidade Estadual de Campinas \\ andrea.oliveira@fca.unicampr.br \\ Akebo Yamakami \\ Universidade Estadual de Campinas \\ akebo@dt.fee.unicamp.br
}

\begin{abstract}
Resumo: A região Centro-Oeste é a maior produtora de grãos do Brasil, sendo o Mato Grosso o maior estado produtor. Atualmente, o Brasil é responsável por cerca de $30 \%$ da produção mundial de soja e ocupa posição como maior exportador. A despeito da posição de destaque no mercado internacional de commodities agrícolas, o Brasil se depara com os gargalos relacionados à infraestrutura logística disponível implicando em perdas concorrenciais. $\mathrm{O}$ objetivo deste estudo é, através da teoria de localização e utilizando programação linear inteira mista, identificar a localização ótima para a instalação de armazéns no estado de Mato Grosso. Os resultados obtidos demonstram que o local ótimo para abertura de novos armazéns depende, em grande medida, da região produtora, além de considerar os custos de frete, armazenagem já disponível e a distância percorrida até os portos de exportação.

Palavras-chave: soja, teoria de localização, pesquisa operacional.
\end{abstract}

Abstract: The Midwest is the largest grain producer region in Brazil, and Mato Grosso being the largest producing state. Currently, Brazil is responsible for about $30 \%$ of world soybean production and holds the position as the largest exporter. In spite of prominence on the international market of agricultural commodities, Brazil is faced with barriers related to available logistics infrastructure resulting in competitive losses. The aim of this study is through the theory of location and using mixed integer linear programming to identify the optimal location for the installation of warehouses in the state of Mato Grosso. The results 
show that the optimum location for opening new stores depends, mostly, the producing region and the costs of freight, warehousing longer available and distance to export ports.

Key words: soybeans, location theory, operations research 


\section{INTRODUÇÃO}

A eficiência brasileira em alguns setores agrícolas é amplamente reconhecida, em especial: soja e derivados, açúcar e álcool, suco de laranja, café e carnes. Parte dessa eficiência deve-se às inúmeras transformações que têm ocorrido na agropecuária brasileira, desde a mudança de foco nas políticas públicas até o acesso ao sistema de crédito rural e aos programas de apoio à agricultura. Destacam-se as mudanças tecnológicas e os investimentos em pesquisas que levaram a elevados ganhos de produtividade $[4,11]$.

A cadeia produtiva da soja é um dos segmentos que colaboram para posição de destaque do agronegócio brasileiro. Segundo o último relatório da United States Department of Agriculture [21], o Brasil é o maior produtor e exportador do grão, superando os Estados Unidos na safra 2013/14, o que evidencia o papel de destaque da soja na economia brasileira, seja em termos de geração de divisas ou para a manutenção da balança comercial superavitária.

O processo de crescimento das exportações das commodities agrícolas brasileiras e a expansão das novas fronteiras agrícolas, promovida por meio de novas tecnologias, têm gerado impactos positivos, mas também revela uma série de deficiências logísticas do País. Tais deficiências - representadas pelas condições precárias das rodovias, pela baixa eficiência das ferrovias e pela desorganização e excesso de burocracia dos portos - tiveram como resultado o aumento das filas de caminhões nos principais portos de exportação, longas esperas de navios para a atracação e o não cumprimento dos prazos de entrega ao mercado internacional. Tudo isso resultou no aumento dos custos e na redução da competitividade dos produtos brasileiros no exterior [6, 17].

O aproveitamento do potencial de expansão da produção de grãos depende do estabelecimento de um sistema eficiente de transporte. Esse deverá comportar volumes maiores a custos menores, permitindo, assim, que o setor de grãos aumente a sua contribuição no abastecimento interno de alimentos e mantenha sua posição no mercado internacional [22].

A questão do escoamento da safra brasileira é fator fundamental que afeta diretamente a comercialização, formação de preços e a própria competitividade do setor. Assim, a infraestrutura logística dever ter capacidade de movimentar e armazenar de modo eficiente toda a produção agrícola nacional $[17,18]$.

Em relação à matriz de transportes, a realidade brasileira está longe do que é proposto na teoria. O ideal seria que países com grandes extensões utilizassem o modal ferroviário para transportar a longas distâncias, muito divergente do que é praticado. No Brasil o modal predominante é o rodoviário, responsável por cerca de 64\% da carga transportada. Em termo de uso do sistema de armazenagem, o mesmo é ainda mais ineficiente, onde em épocas de safras, não há local para armazenar toda a produção agrícola do país [2].

Quando se analisa a questão logística brasileira, percebe-se que, além do sistema de transporte, a infraestrutura de armazenagem no Brasil também não tem acompanhado o ritmo de crescimento da produção agrícola.

A capacidade de armazenar, de forma adequada, a safra agrícola é essencial para a cadeia logística. Mesmo com as funções clássicas do armazenamento, em especial, a manutenção da qualidade das matérias-primas, no agronegócio estas funções se ampliam. Isso porque uma rede adequada é capaz de promover a venda do produto em melhores épocas do ano (melhores preços e menores custos com transporte), evitando o chamado "rush de vendas", e impede o congestionamento durante o escoamento da produção em períodos de safra, especialmente nos portos.

Dessa maneira, o objetivo do trabalho é avaliar a localização da rede de armazenagem do Estado do Mato Grosso e, num segundo momento, indicar uma distribuição ótima para os armazéns. Para tanto, é utilizado um modelo de programação linear inteira mista para otimização da armazenagem, a fim de encontrar o ponto ótimo para a instalação de armazéns. 
No capítulo 2, é apresentada uma breve revisão referente à soja brasileira e a teoria de localização. No capítulo 3, é apresentada a metodologia utilizada. No capítulo 4, os resultados obtidos e no capítulo 5, uma breve conclusão.

\section{REVISÃO DE LITERATURA}

\subsection{A SOJA BRASILEIRA}

O complexo da soja (grão-farelo-óleo) é a principal cadeia agroindustrial que mais gera fluxos positivos para exportação no Brasil, exigindo que a infraestrutura logística esteja preparada para atender sua demanda. O Brasil é responsável por cerca de $30 \%$ da produção mundial de soja, superando os Estados Unidos. A previsão para safra 2013/14 é que o Brasil ficará em primeiro lugar no ranking mundial de exportação, responsável por $41 \%$ dos fluxos comerciais realizados no mundo [21].

A predominância da soja na região Centro-Oeste foi fruto de pesquisas que buscavam expandir a área plantada do produto, que até então era apenas produzido na região Sul. Uma série de tecnologias foi desenvolvida até que o solo e clima do cerrado se tornassem aptos a receber a cultura. Com a quebra desta barreira produtiva, a soja acaba conquistando novas fronteiras agrícolas e passa a ser produzida nas regiões que possuíam clima tropical [19]. Com a expansão da produção da soja no Brasil, esta cultura hoje ocupa a posição da principal commodity agrícola produzida e exportada no país. Atualmente, a região Centro-Oeste é a maior produtora de soja, sendo o estado do Mato Grosso o principal, produzindo 27,2\% do total brasileiro na safra 2010/11 [13].

O estado do Mato Grosso se destaca na região Centro-Oeste devido ao seu desenvolvimento social e econômico que possui como base o setor agrícola e suas relações a montante e a jusante [8].

Durante a safra de 2012/2013 todas as regiões brasileiras sofreram aumento na quantidade produzida, exceto a região Sul, que devido à instabilidade climática passou por um período rigoroso de estiagem. Tal fato não comprometeu a safra e o desempenho da cultura nas diversas regiões do país, que se mostrou superior ao que se era previsto para o período, gerando uma "super-safra".

Esta condição de super-safra faz com que as condições logísticas acabaram se tornando um gargalo mais grave do que aquele apresentado nos últimos anos.

a região Centro-Oeste, mesmo com seu grande desempenho na produção agrícola, não possui condições adequadas para escoamento da produção de grãos. A movimentação da soja no Estado é feita através do modal rodoviário, onde as condições das estradas acabam trazendo prejuízo para as commodities brasileiras. A cada final de safra a quantidade perdida de grãos nas estradas aumenta, assim como as condições dos armazéns, principalmente aqueles que estão localizados nas propriedades dos produtores rurais, não são adequados para a armazenagem da soja.

A dificuldade nas condições de armazenamento de grãos faz com que os produtores comercializem seus produtos logo a pós colheita, período o qual o preço das commodities ainda encontram-se baixos e os valores dos fretes estão altos. A falta de infraestrutura adequada para armazenamento além de gerar perdas para o produtor, afeta diretamente os terminais portuários, estes por sua vez, ficam plugados em curto período de tempo, pois não comportam o alto fluxo no pós-colheita [5, 12].

A soja, por ser um produto de baixo valor agregado e de altos volumes, necessita de um modal de transporte que seja de baixo custo e de grande capacidade. O modal rodoviário, o qual deveria ser destinado a curtas distâncias e para fazer o translado do local produzido até os armazéns ou até os terminais ferroviários ou hidroviários, acaba realizando todo o transporte, gerando uma ineficiência logística [5, 6]. 
A insuficiência dos modais hidroviários e ferroviários no Brasil acaba fazendo com que a soja seja transportada, em sua maioria, pelo modal rodoviário, e este por sua vez, apresenta custos maiores para curtas distâncias. Os gargalos não só refletem em aumentos de custos, mas também em perdas de eficiência. Os principais terminais portuários para exportação de soja são o de Paranaguá e Santos, o tempo de transporte acaba sendo de 6 a 8 vezes maior do que se fosse transportado via hidrovia, por exemplo.

\subsection{TEORIA ESPACIAL: ANÉIS DE THUNEN}

A Análise Espacial pode ser entendida como o conjunto de procedimentos analíticos feitos sobre dados de natureza espacial que auxiliam a tomada de decisões [14]. O primeiro modelo espacial-regional foi desenvolvido por Johann Heinrich Von Thünen em 1826 e teve a preocupação de adicionar uma análise dos espaços agrícolas em sua metodologia. Os "Anéis de Thünen” é o primeiro estudo metodológico que acrescenta a noção de espaço na atividade econômica, onde o autor busca delimitar a produção agrícola através de circunferências ao redor dos municípios [3].

A hipótese de Thünen é de que a produção agrícola determina a organização do espaço, de forma que cada atividade deve estar situada numa distância do centro urbano. A teoria está baseada na existência de uma quantidade limitada de terras e no fato de que, quando a terra está localizada próximo das cidades - ou nas regiões centrais, o preço da terra aumenta $[3,10]$.

Von Thünen, através de um sistema de equações matemáticas, conseguiu chegar num modelo de equilíbrio estático que explica a distribuição das atividades agrícolas na terra [10].

O modelo é baseado numa situação hipotética onde se deve disseminar a produção de produtos agrícolas em alguma planície (isolada do mundo), cujos custos de produção e de transportes são constantes, onde o único mercado consumidor está localizado na região central, e o objetivo é maximizar os lucros da produção agrícola [1, 3].

A atividade mais adjunta ao centro, o primeiro anel, são os hortifrutigranjeiros, sua localização é ilustrada pelo fato de que os produtos são de alto grau de perecibilidade e, portanto devem estar mais próximo ao centro, além desses produtos serem de rápido consumo, e uma distância mais extensa não seria viável. Outro fator que podemos atribuir a tal localização é que a agricultura depende de fertilizantes, que são adquiridos em grandes centros urbanos, dessa forma, a circunvizinhança com a cidade é vital para o sucesso desta atividade agropecuária [1].

Mesmo que Thünen tenha configurado um modelo teórico para arranjar o espaço somente da produção agrícola, definindo o espaço rural como sinônimo de espaço agrícola, esta teoria influenciou outros trabalhos em diversos ramos e áreas de atuação da geografia, como Walter Christaller (1933) no espaço urbano e Leo Waibel (1948) no espaço rural. A aplicação do modelo de Von Thünen não tem uma escala única, pode abranger o desenvolvimento local, regional ou nacional $[1,3]$.

A participação do custo de transporte nos custos totais dos produtos tem se demonstrado cada vez menor, logo criticam a importância dada aos custos de transporte na determinação da localização de firmas de Weber [1,3]. Os custos de transporte podem até não ser importante para casos de produtos com alto valor agregado, porém no caso de commodities agrícolas ainda tem grande relevância.

\section{METODOLOGIA}

No presente estudo fez-se uso da modelo proposto por Oliveira [15], que trabalha com a localização ótima de armazéns de açúcar do Estado de São Paulo para exportação. O modelo aqui proposto foi adaptado e possui como objetivo determinar a localização ótima de 
armazéns dedicados para soja do Estado do Mato Grosso com vistas à exportação. Espera-se, portanto, minimizar o custo logístico de transporte em função das restrições de capacidade de armazenamento.

Na busca de quantificar a oferta de soja no Estado do Mato Grosso, utilizou-se os dados do IBGE da produção de 2012. Foram consideradas para compor a amostra as 10 maiores microrregiões1 produtoras de soja, sendo elas: Alto teles Pires, Parecis, Canaranã, Sinop, Arinos, primavera do Leste, Rondonópolis, Norte Araguaia, Tesouro e Paranatinga, que correspondem a 92,11\% de toda produção estadual.

É importante destacar que não está disponível a quantidade total exportada de cada microrregião mato-grossense, portanto no presente estudo adotou-se o coeficiente de participação de cada microrregião na produção total do Estado sobre o volume de exportação total estadual que é de $60 \%$ da produção, resultando em uma estimativa das exportações por microrregião. Logo, adotou-se que $60 \%$ do total produzido por cada microrregião tem como destino a exportação.

Já na quantificação da demanda, considerou-se o volume de exportações do Estado do Mato Grosso por meio dos principais portos, são eles: Santos (SP) e Paranaguá (PR), que representam $86,72 \%$ de todo volume escoado de soja com destino a exportação.

A Figura 1 apresenta o esquema do modelo proposto, no qual são representados 10 microrregiões produtoras (MRi), 22 microrregiões (Aj) possíveis candidatas para a instalação de armazéns de tamanho t (considerou-se 21 diferentes tamanhos) e dois portos (Pu) com diferentes demandas. A produção de cada microrregião tem dois destinos: o primeiro sendo o transporte rodoviário direto para o porto u (wiu); e o segundo sendo o transporte rodoviário para o armazém localizado em j (xij), seguindo depois por transporte rodo-ferroviário para u (yju). A alternativa hidroviária não foi considerada, pois não há relevância para as rotas logísticas utilizadas no modelo proposto.

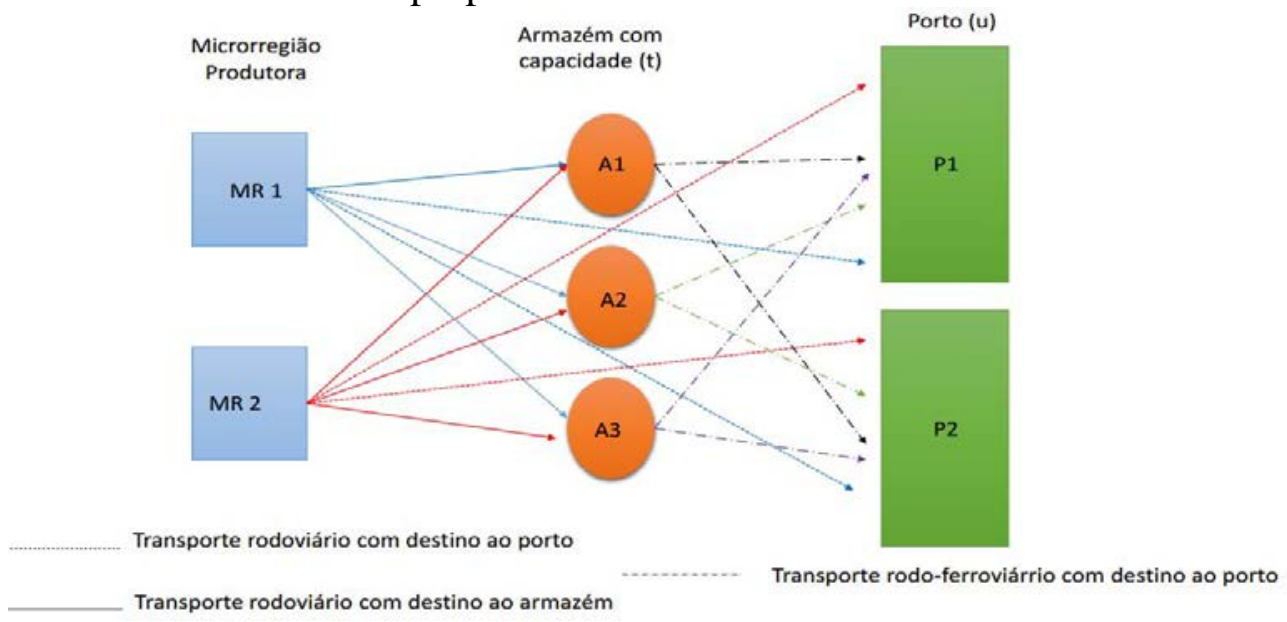

Figura 1. Diagrama do modelo proposto

Fonte: Elaboração própria a partir de [15].

Como possíveis locais candidatos para a instalação de armazéns, foram consideradas as 22 microrregiões mato-grossenses. São elas: Alto Teles Pires, Parecis, Canarana, Sinop, Arinos, Primavera do Leste, Rondonópolis, Norte Araguaia, Tesouro, Paranatinga, Aripuanã, Alto Araguaia, Tangará da Serra, Colíder, Alto Paraguai, Cuiabá, Alto Guaporé, Médio Araguaia, Rosário Oeste, Alto Pantanal, Jauru, Alta Floresta. Vale ressaltar que não foi restrito no modelo a quantidade de armazéns por microrregião.

\footnotetext{
${ }^{1}$ Microrregião é um agrupamento de municípios limítrofes. Este agrupamento é utilizado pelo IBGE para fins estatísticos e com base em similaridades econômicas e sociais.
} 
No modelo foram considerados 21 diferentes tamanhos, que indicam a capacidade dinâmica em toneladas dos armazéns. São eles: 1.000, 2.000, 3.000, 4.000, 5.000, 6.000, 7.000, 8.000, 9.000, 10.000, 20.000, 30.000, 40.000, 50.000, 60.000, 70.000, 80.000, 90.000, 10.0000, 15.0000 e 20.0000. Estes tamanhos foram definidos com base nos armazéns que já existem nas microrregiões mato-grossenses.

Os custos operacionais de armazenagem tiveram como base Ferrari [9], que considera os valores mensais das tarifas de recepção, de limpeza, de secagem, de expedição e de armazenamento, totalizando aproximadamente um valor de $\mathrm{R} \$ 16,87 / \mathrm{t}$ e trazendo para o valor presente tem-se R $\$ 17,86 /$ t. Como todos os custos no modelo são dados em dólares, utilizouse o câmbio de R \$2,29/US\$1,00 para estimar um custo operacional fixo por tonelada de US\$ 7. Vale ressaltar que o modelo não considera economias de escala, logo, o custo foi calculado multiplicando o valor estimado de US\$ 7,00/t pela capacidade dinâmica do armazém.

Por fim, os dados referentes aos fretes rodoviários e ferroviários, em dólar, foram fornecidos pelo Sistema de Informações de Fretes [20], enquanto dados referentes ao transbordo $^{2}$ e à tarifa portuária tiveram como base [15, 17]. O custo portuário considerado no modelo foi de US\$7/t para o porto de Santos (SP) e de US\$7,5/t para o porto de Paranaguá (PA). O software utilizado para otimização foi o GLPK, versão 4.34.

No modelo, a função objetivo busca minimizar os custos obtidos na exportação da soja matogrossense, logo tem-se:

$$
\operatorname{Min} Z(x)=\sum_{i=1}^{10} \sum_{j=1}^{22} c_{i j} x_{i j}+\sum_{j=1}^{22} \sum_{u=1}^{2} a_{j u} y_{j u}+\sum_{i=1}^{10} \sum_{u=1}^{2} p_{i u} w_{i u}+\sum_{u=i}^{2} C P_{u} d_{u}+\sum_{j=1}^{22} H_{j}
$$

Onde :

$c_{i j}=$ Custo de transporte rodoviário por tonelada entre a microrregião i e o armazém localizado em j;

$x_{i j}=$ Quantidade transportada da microrregião i ao armazém localizado em j;

$a_{j u}=$ Custo do transporte ferroviário do armazém localizado em j ao porto u;

$y_{j u}=$ Quantidade transportada do armazém localizado em j ao porto u;

$p_{i u}=$ Custo de transporte rodoviário por toneladas da microrregião i ao porto u;

$w_{i u}=$ Quantidade transportada diretamente da microrregião i ao porto u;

$C P_{u}=$ Custo portuário por tonelada de soja;

$d_{u}=$ Quantidade de soja que chega no porto;

$\mathrm{Hj}$ = Custo Operacional do armazém localizado em j.

\section{Restriç̧ões:}

1. Oferta das microrregiões matogrossenses: a quantidade de soja transportada da microrregião i diretamente para o u somado a quantidade transportada de microrregião i para armazém localizado em j deve ser menor ou igual a capacidade produtiva da microrregião i.

\footnotetext{
${ }^{2}$ Refere-se a transferência de uma carga de um modal para outro, pode acontecer também na mudança de um veículo a outro.
} 
$\sum_{j=1}^{22} x_{i j}+\sum_{u=1}^{2} w_{i u} \leq M_{i}$, para todo $i$

Onde :

$M_{i}$ = Capacidade de produção das microrregiões com destino a exportação

2. Capacidade dos armazéns: a quantidade em toneladas de soja que chega no armazém localizado em j, da microrregião i, não deve ser maior que a capacidade dinâmica do armazém.

$\sum_{i=1}^{10} x_{i j} \leq \sum_{t=1}^{21} \operatorname{cap}_{t} z_{j t}$, para todo $j$

Onde:

$\operatorname{cap}_{t}=$ Capacidade dinâmica do armazém de tamanho t localizado em j.

$z_{j t}=$ variável binária, 1 se o armazém de tamanho t for instalado em j, 0 caso contrário.

3. Estoque zero: no modelo não se leva em consideração estoque no armazém, logo a quantidade de soja que entra no armazém é igual a quantidade que sai do armazém.

$$
\sum_{i=1}^{10} x_{i j}=\sum_{i=1}^{10} y_{j u} \text {, para todo } j \text {. }
$$

4. Demanda do porto u: a demanda do porto u deve ser respeitada.

$\sum_{j=1}^{22} y_{j u}+\sum_{i=1}^{10} w_{i u} \geq e_{u}$, para todo $u$.

Onde:

$e_{u}=$ demanda do porto u.

5. Custo operacional do armazém de tamanho $t$

$H_{j}=\sum_{t=1}^{21} \mathrm{CO}_{t} z_{j t}$, para todo $j$

Onde:

$$
\begin{aligned}
& \mathrm{CO}_{t}=\text { custo operacional do armazém de tamanho } t_{;} \\
& z_{j t}=\left\{\begin{array}{l}
1, \text { se for instalado o armazém de tamanho } t \text { localizado em } j \\
0, \text { caso contrário }
\end{array}\right.
\end{aligned}
$$

A restrição acima não leva em consideração economia de escala de armazenagem, ou seja, independente do volume que passe pelo armazém o custo de utilização será o mesmo.

\section{RESULTADOS E DISCUSSÕES}

A Tabela 1 indica a quantidade ótima transportada da microrregião i para o armazém localizado na microrregião j. O eixo x considera as 10 maiores microrregiões produtoras de soja no Mato Grosso, enquanto o eixo y considera as 22 microrregiões no mesmo estado, possíveis candidatas para armazenamento da produção.

Como observado na Tabela 1, a microrregião produtora Alto Teles Pires, armazena 945 mil de toneladas de sua produção e envia 745 mil de toneladas para Rosário Oeste. 
Tabela 1. Quantidade transportada da microrregião para o armazém ótimo (em mil toneladas)

\begin{tabular}{|c|c|c|c|c|c|c|c|c|c|c|}
\hline & 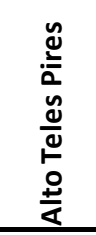 & 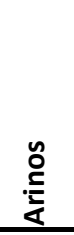 & 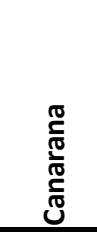 & 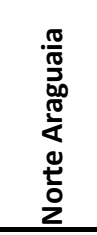 & 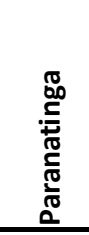 & 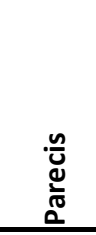 & 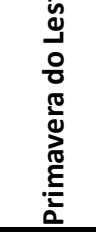 & 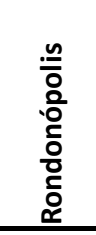 & $\stackrel{\circ}{\stackrel{\circ}{5}}$ & 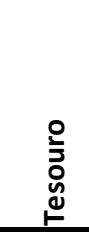 \\
\hline \multicolumn{11}{|l|}{ Alta Flores } \\
\hline \multicolumn{11}{|l|}{ Alto Guaporé } \\
\hline \multicolumn{11}{|l|}{ Alto Araguaia } \\
\hline \multicolumn{11}{|l|}{ Alto Pantanal } \\
\hline Alto Paraguai & & & & & & 682,0 & & & & \\
\hline Altor Teles Pires & 945,0 & & & & & & & & & \\
\hline \multicolumn{11}{|l|}{ Arinos } \\
\hline \multicolumn{11}{|l|}{ Aripuanã } \\
\hline Canarana & & & 935,0 & & & & & & & \\
\hline Colíder & & & & & & & & & 200,0 & \\
\hline \multicolumn{11}{|l|}{ Cuiabá } \\
\hline Jauru & & & & & & 200,0 & & & & \\
\hline \multicolumn{11}{|l|}{ Médio Araguaia } \\
\hline Norte Araguaia & & & & 209,0 & & & & & & \\
\hline Paranatinga & & & & & 398,0 & & & & & \\
\hline \multicolumn{11}{|l|}{ Parecis } \\
\hline Primavera do leste & & & & & 6,3 & & 710,8 & & & 277,9 \\
\hline Rondonópolis & & & & & & & & 763,3 & & 181,7 \\
\hline Rosário Oeste & 745,0 & & & & & & & & & \\
\hline Sinop & & & & & & & & & 553,0 & \\
\hline Tangará da Serra & & & & & & 745,0 & & & & \\
\hline Tesouro & & & & & & & 90,0 & & & \\
\hline \multicolumn{11}{|l|}{ Porto de Pará } \\
\hline Porto de Santos & & & & & & & & & & 1,7 \\
\hline
\end{tabular}

Fonte: Elaboração própria a partir de dados de pesquisa

A Tabela 2 consiste na quantidade transportada do armazém j para o Porto u. O eixo X indica os Portos de Santos e Paranaguá, os quais foram considerados no modelo. E o eixo Y, indica as 22 microrregiões matogrossenses candidatas a instalação ótima de armazéns.

Observando a Tabela 2, é possível verificar que Alto Paraguai envia para ambos os portos analisados, sendo 75,7 mil toneladas para o Porto de Santos e 606, 3 mil toneladas de soja para o Porto de Paranaguá. Sinop e Tesouro, enviam apenas para o Porto de Paranaguá, sendo respectivamente 553 mil toneladas e 90 mil toneladas a quantidade transportada de 
soja. As demais regiões transportam soja apenas para o Porto de Santos totalizando 5.522 mil toneladas do grão. Do total da produção matogrossense considerada no presente estudo, 83,54\% é escoada pelo Porto de Santos.

Tabela 2. Quantidade transportada do armazém ótimo até o porto de exportação (em mil toneladas).

\begin{tabular}{l|c}
\hline \multicolumn{1}{c|}{$\mathbf{y}(\mathbf{j}, \mathbf{u})$} & P. Santos \\
\hline Alta Floresta & \\
\hline Alto Guaporé & \\
\hline Alto Araguaia & \\
\hline Alto Pantanal & \\
\hline Alto Paraguai & 75,7 \\
\hline Alto Teles Pires & 945,0 \\
\hline Arinos & \\
\hline Aripuanã & \\
\hline Canarana & 935,0 \\
\hline Colíder & 200,0 \\
\hline Cuiabá & \\
\hline Jauru & 200,0 \\
\hline Médio Araguaia & \\
\hline Norte Araguaia & 209,0 \\
\hline Paranatinga & 398,0 \\
\hline Parecis & \\
\hline Primavera do Leste & 945,0 \\
\hline Rondonópolis & 945,0 \\
\hline Rosário Oeste & 745,0 \\
\hline Sinop & \\
\hline Tangará da Serra & 745,0 \\
\hline Tesouro & \\
\hline
\end{tabular}

Fonte: Elaboração própria a partir de dados de pesquisa 
Os resultados descritos na Tabela 3 indicam a localização ótima para instalação de armazéns e suas respectivas capacidades dinâmicas. No eixo X, constam as 22 microrregiões possíveis candidatas para instalação de armazéns, enquanto o eixo Y compreende as 21 diferentes capacidades dinâmicas testadas no modelo.

Das 22 microrregiões candidatas a instalação de armazéns, Alto Floresta, Alto Guapore, Alto Araguaia, Alto Pantanal, Arinos, Aripuanã, Cuiabá, Médio Araguaia e Parecis o modelo obteve como resultado nenhuma instalação de armazéns para as mesmas, o que pode ser justificado pelo custo de armazenagem, pela distância entre a microrregião produtora e destino final, e geografia local.

Tabela 3. Localização ótima para instalação de armazéns.

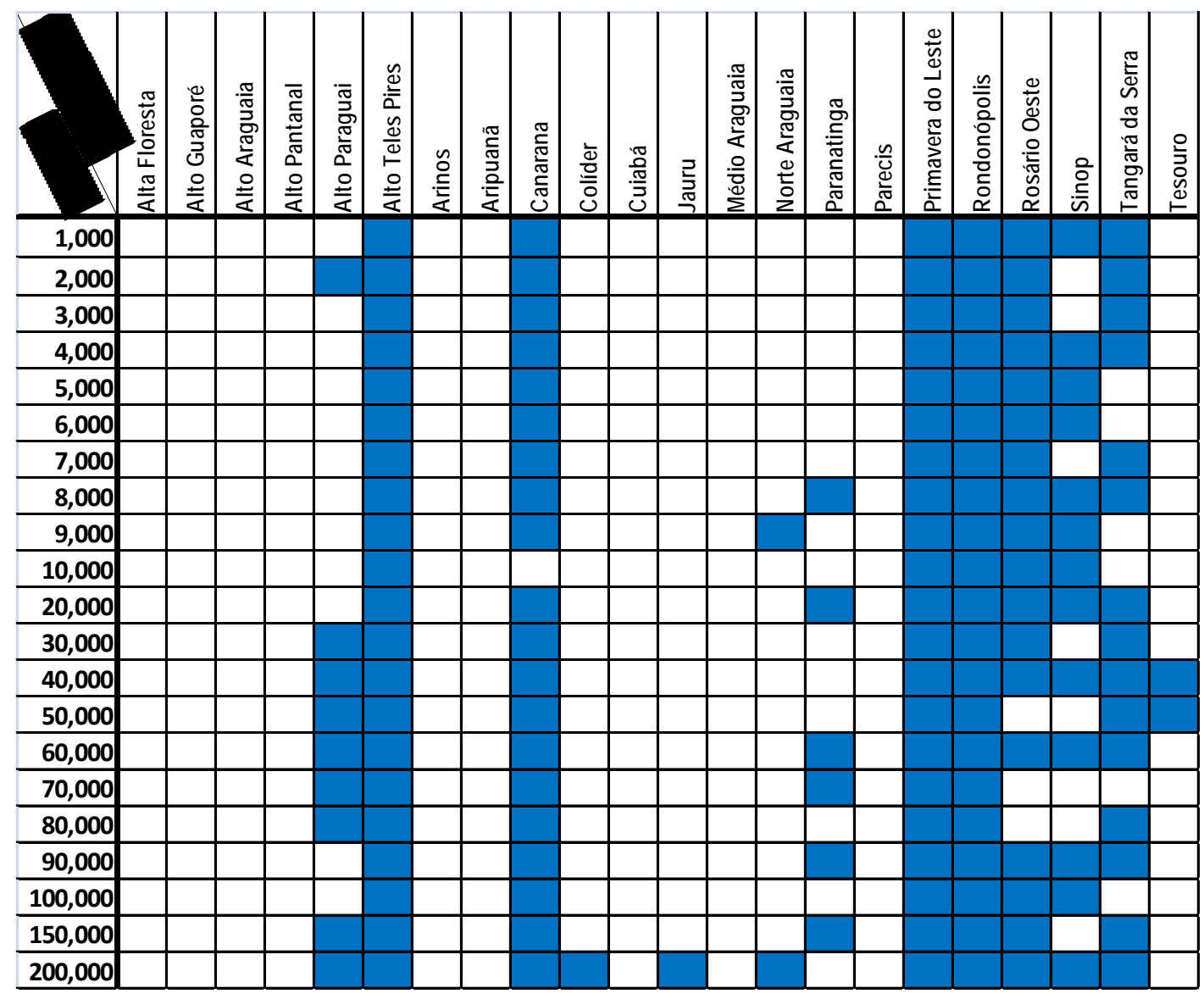

Fonte: Elaboração própria a partir de dados de pesquisa.

\section{CONSIDERAÇÕES FINAIS}

O Complexo da Soja, juntamente com o milho, somam aproximadamente $80 \%$ das exportações de grãos do país. A expansão das fronteiras agrícolas e as novas tecnologias, fez com que regiões afastadas dos portos de exportação, caso da região Centro-Oeste, criasse um grande potencial de produção agrícola.

O sistema logístico brasileiro é ineficiente em diversos pontos, seja na matriz de transporte, a qual não trabalha com a capacidade adequada para cada modal, seja no sistema de armazenagem, o qual o Brasil não dispõe de quantidade suficiente de armazéns para resguardar toda a produção agrícola nacional na época de safra. 
É importante destacar as condições internacionais favoráveis do mercado da soja e a competitividade do país na produção desse grão, alterações nesse mercado podem alterar a dinâmica do setor e por consequência o resultado ótimo obtido no modelo.

Conclui-se que a viabilidade de instalação de armazéns pode ser bastante dependente das microrregiões produtoras e em especial os custos com fretes e armazenagem, além de considerar suas distâncias em relação aos portos.

Para estudos futuros, sugere-se considerar outros portos de exportação de soja, assim como outras rotas intermodais, as quais podem incluir também o modal hidroviário, abrangendo a realidade do sistema logístico brasileiro. Além de analisar outros cenários, considerando também regiões com menor produção, a fim de visualizar se a localização ótima dos armazéns é alterada ser alterado, comprovando que a capacidade produtiva da região influencia na localização do armazém.

\section{REFERÊNCIAS}

[1] ALVES, F. D. Notas Teórico-Metodológicas entre Geografia Econômica e Desenvolvimento Regional. In: V Seminário Internacional sobre Desenvolvimento Regional, 2011, Santa Cruz do Sul - RS. CEPAL 60 anos de Desenvolvimento na América Latina. Santa Cruz do Sul: UNISC, 2011. v. 5.

[2] ANTT: Agência Nacional de Transportes Terrestres (2006). Relatório Anual 2006. Disponível em:<http://www.antt.gov.br/default.asp>. Acesso em: 02 jan. 2010.

[3] AZZONI, C. R. Teoria da localização: análise crítica a partir das evidências empíricas no Estado de São Paulo. 1982. 287 p. Tese (Doutorado), USP, São Paulo, 1982.

[4] BARROS, G. S. C. Política Agrícola no Brasil: subsídios e investimentos. In: GASQUES, J. G.; VIEIRA FILHO, J. E. R.; NAVARRO, Z. (Org.). A Agricultura Brasileira: desempenho, desafios e perspectivas. Brasília: Ipea, 2010. 298 p.

[5] CAIXETA FILHO, J. V. Especificidade das modalidades de transporte para a movimentação de produtos agrícolas (2001). In: CAIXETA- FILHO, J. V.; GAMEIRO, A. H. (Org.). Transporte e Logística em Sistemas Agroindustriais. São Paulo, SP: Atlas, 218p.

[6] CAIXETA FILHO, J. V. Pesquisa operacional aplicada ao sistema agroindustrial. São Paulo: Atlas, 1997.

[7] CORREA, V.H. C. RAMOS, P. A precariedade do transporte rodoviário brasileiro para o escoamento da produção de soja do Centro-Oeste: situação e perspectivas. Rev. Econ. Sociol. Rural, Brasília, v. 48, n. 2, Junho 2010.

[8] EMBRAPA. Tecnologias de Produção de Soja - Região Central do Brasil - 2001/2002. Outubro de 2001.

[9] FERRARI, R. C. Utilização de modelo matemático de otimização para identificação de locais para instalação de unidades armazenadoras de soja no estado do Mato Grosso. 2006. Dissertação (Mestrado em Economia Aplicada) - Escola Superior de Agricultura Luiz de Queiroz, University of São Paulo, Piracicaba, 2006.

[10] FERREIRA, C. M. C. A evolução das teorias clássicas da economia espacial: suas contribuições para a análise de concentração das atividades. Belo Horizonte: UFMG (Centro de Desenvolvimento e Planejamento Regional), 1975.

[11] GASQUES, J. G. et al. Produtividade Total dos Fatores e transformações da agricultura brasileira: análise dos dados dos censos agropecuários. In: GASQUES, J. G.; VIEIRA FILHO, J. E. 
R.; NAVARRO, Z. (Org.). A Agricultura Brasileira: desempenho, desafios e perspectivas. Brasília: Ipea, 2010. 298 p.

[12] KUSSANO, M. R.; BATALHA, M. O. Custos logísticos agroindustriais: avaliação do escoamento da soja em grão do Mato Grosso para o mercado externo. Gest. Prod., 2012, vol.19, no.3, p.619-632.

[13] LAVORENTE, G. B. Caracterização das vias de exportação e soja do Estado do Mato Grosso. ESALQ-Log. Piracicaba, 2011.

[14] MATOS, G. S. d. O modelo de von thünen: um aplicativo Computacional. Dissertação. Belo horizonte: Pontifícia universidade católica de Minas Gerais, 2005.

[15] OLIVEIRA, A. M. K.; CAIXETA FILHO, J. V. Potencial da logística ferroviária para exportação de açúcar em São Paulo: recomendações de localização para armazéns intermodais. Revista de Economia e Sociologia Rural, Out./Dec. 2007, vol.45, no.4, p.823-853.

[16] OLIVEIRA, A. L. R. Transporte de soja do estado do Mato Grosso para exportação: uma aplicação de programação linear. Revista de Economia Agrícola, São Paulo, v. 54, 2007, p. 33-41.

[17] OLIVEIRA, A. L. R.; SILVEIRA, J. M. F. J.; ALVIM, A. M. Cartagena protocol, biosafety and grain segregation: the effects on the soybean logistics in Brazil. E3 Journal of Agricultural research and development, v. 2, p. 17-30, 2012.

[18] OLIVEIRA, A. L. R. O; SILVEIRA, J. M. J. F. Restructuring of the corn supply chain in Brazil: facing the challenges in logistics or regulation of biotechnology. The International Food and Agribusiness Management Review, v. 16, p. 1-24, 2013

[19] PONTES, H. L. J. ; CARMO, B. B. T ; PORTO, A. J. V . Problemas Logísticos na Exportação Brasileira da Soja em Grão. S \& G. Sistemas \& gestão, v. 4, p. 155-181, 2009.

[20] SIFRECA. Sistema de Informações de Fretes. (2011). Fretes Rodoviários e Ferroviários Milho 2011. Disponível em: http://sifreca.esalq.usp.br/sifreca/pt/index.php. Acesso em: abr. 2012.

[21] USDA. United States Departament of Agriculture. Production, Supply and Distribution Database. Disponível em: <http://www.fas.usda.gov/psdonline/psdHome.aspx>. Acesso em: mar. 2014.

[22] WRIGHT, C.L. Análise econômica de transporte e armazenagem de grãos: estudo do corredor de exportação de Paranaguá. Brasília: GEIPOT, 1980. 187 p. 